\title{
Pengaruh Growth Opportunity, Net Working Capital, Cash Conversion Cycle Dan Dividend Payout Terhadap Cash Holding (Studi Empiris Pada Perusahaan Sektor Industri Barang Konsumsi Yang Terdaftar Di Bursa Efek Indonesia Tahun 2015-2018)
}

\author{
Nanda Setyaningrum ${ }^{1}$, Erma Setiawati ${ }^{2}$ \\ Jurusan Akuntansi Fakultas Ekonomi dan Bisnis, Universitas Muhammadiyah Surakarta ${ }^{1}$, \\ Fakultas Ekonomi dan Bisnis, Universitas Muhammadiyah Surakarta ${ }^{2}$ \\ Email korespondensi : nsetya123@gmail.com
}

\begin{abstract}
Abstrak: Penelitian ini bertujuan untuk mengetahui pengaruh growth opportunity, net working capital, cash conversion cycle, dan dividend payout terhadap cash holding perusahaan sektor industri barang konsumsi yang terdaftar di Bursa Efek Indonesia. Desain penelitian ini adalah penelitian asosiatif kausal. Populasi dari penelitian ini adalah perusahaan sektor industri barang konsumsi yang terdaftar si Bursa Efek Indonesia. Periode penelitian yang digunakan yaitu periode 20152018. Sampel dalam penelitian ini diperoleh dengan metode purposive sampling. Berdasarkan kriteria yang ada, didapatkan 19 perusahaan yang menjadi sampel penelitian. Data yang digunakan adalah data sekunder. Teknik analisis data dengan menggunakan analisis regresi linier berganda dengan menggunakan SPSS versi 21. Hasil penelitian menunjukkan bahwa net working capital dan cash conversion cycle berpengaruh terhadap cash holding, sedangkan growth opportunity dan dividend payout tidak berpengaruh terhadap cash holding.
\end{abstract}

Kata Kunci: Cash Holding, Growth Opportunity, Net Working Capital, Cash Conversion Cycle, Dividend Payout

Masalah yang sering dihadapi oleh manajer keuangan dalam menjalankan kegiatan operasional perusahaan adalah menjaga keseimbangan jumlah kas perusahaan. Semakin pentingnya menjaga keseimbangan jumlah kas perusahaan, maka semakin banyak perhatian dari berbagai pihak seperti manajer dan investor terhadap penentuan cash holding (Al-Najjar, 2013; Jamil et al, 2016). Secara umum tingkat cash holding yang tinggi mungkin disebabkan karena adanya keinginan manajer untuk mempertahankan aset likuid di bawah kendalinya, sehingga akan menimbulkan masalah keagenan dalam perusahaan tersebut.

Subramanyam et al. (2011) menyatakan bahwa perusahaan yang memiliki jumlah kas optimal dapat terhindar dari krisis ekonomi dengan masuk ke pasar modal, sedangkan perusahaan yang memiliki jumlah kas yang rendah akan kesulitan dalam menghadapi krisis ekonomi akibatnya perusahaan tidak mampu menjalankan kegiatan operasionalnya. Hal tersebut mengindikasikan bahwa perusahaan dengan tingkat cash holding rendah tidak mampu bertahan lama disaat krisis ekonomi karena mereka tidak memiliki dana yang cukup untuk menjalankan kegiatan 
operasionalnya seperti membeli bahan baku yang semakin mahal, membayar tenaga kerja dan lainnya.

Salah satu faktor yang dapat digunakan untuk menganalisis kebijakan cash holding adalah growth opportunity atau kesempatan pertumbuhan. Growth opportunity adalah suatu perpaduan antara kemungkinan peluang investasi di masa depan dengan aset nyata yang dimiliki oleh suatu perusahaan (William dan Fauzi, 2013). Sesuai dengan motif spekulatif, perusahaan menahan kas untuk peluang investasi yang menguntungkan, maka perusahaan dengan peluang investasi tinggi akan menahan kas dalam jumlah yang besar guna membiayai kesempatan investasi tersebut.

Hasil penelitian Saputri (2019) menyatakan bahwa growth opportunity berpengaruh positif terhadap cash holding. Namun hasil penelitian berbeda diungkapkan oleh Wulandari (2019) dan Simanjuntak (2017) yang menyatakan bahwa Growth Opportunity tidak berpengaruh signifikan terhadap cash holding.

Faktor kedua yang mempengaruhi cash holding adalah net working capital atau modal kerja bersih. Menurut konsep kualitatif modal kerja bersih adalah bagian dari aset lancar yang dapat digunakan untuk membiayai kegiatan operasional perusahaan tanpa mengganggu likuiditas perusahaan tersebut (Riyanto, 2001). Net working capital atau modal kerja bersih diperoleh dari aset lancar perusahaan dikurang dengan kewajiban lancar dan dibagi dengan total aset. Jika hasil perhitungan modal kerja bersih perusahaan negatif maka diperkirakan perusahaan sedang mengalami kesulitan likuiditas sehingga perusahaan akan menahan kas lebih banyak. (Rahmawati, 2014).

Hasil penelitian Wulandari (2019) menyatakan bahwa net working capital berpengaruh positif terhadap cash holding. Sedangkan hasil penelitian Simanjuntak (2017) menyatakan bahwa net working capital memiliki pengaruh negatif terhadap cash holding. Namun hasil penelitian berbeda diungkapkan oleh Maarif (2009) yang menyatakan bahwa net working capital tidak berpengaruh terhadap cash holding

Faktor berikutnya yang mempengaruhi cash holding adalah cash conversion cycle. Syarief et al (2009) mengartikan cash conversion cycle sebagai waktu dalam satuan hari yang dibutuhkan untuk mendapatkan kas dari hasil kegiatan operasional perusahaan yaitu dari penagihan piutang ditambah penjualan persediaan dikurangi dengan pembayaran utang. Perusahaan yang mengalami siklus konversi kas yang lama akan menahan kas lebih besar untuk menghindari financial distress (Safitri, 2016).

Hasil penelitian Humendru (2018) menyatakan bahwa cash conversion cycle berpengaruh positif signifikan terhadap cash holding. Sedangkan hasil penelitian Wulandari (2019) menyatakan bahwa cash conversion cycle berpengaruh negatif signifikan terhadap cash holding. Namun hasil penelitian berbeda diungkapkan oleh Senjaya (2016) yang 
menyatakan bahwa cash conversion cycle tidak berpengaruh terhadap cash holding.

Faktor keempat yang mempengaruhi cash holding adalah dividend payout. Dividen adalah besaran laba yang diperoleh dari hasil kegiatan operasional perusahaan untuk menjadi hak investor berdasarkan keputusan dalam Rapat Umum Pemegang Saham (RUPS) (Hapsari, 2015). Berdasarkan teori trade-off, hubungan antara pembayaran dividen dan cash holding harus negatif, karena perusahaan yang membayar dividen dapat menukar biaya marginal memegang kas dengan mengurangi pembayaran dividen tersebut (AI-Najjar \& Belghitar 2011).

Hasil penelitian Wenny (2017) menyatakan bahwa dividend payout berpengaruh positif signifikan terhadap cash holding. Sedangkan hasil penelitian Wulandari (2019) dan Feri Osa (2016) menyatakan bahwa dividend payout tidak berpengaruh signifikan terhadap cash holding.

Perusahaan industri barang konsumsi terdiri dari subsektor makanan dan minuman, subsektor rokok, subsektor farmasi, subsektor kosmetik dan keperluan rumah tangga, serta subsektor peralatan rumah tangga. Perkembangan perusahaan sektor industri barang konsumsi di Indonesia sangat pesat, hal ini dapat dilihat dari semakin banyaknya perusahaan yang terdaftar di Bursa Efek Indonesia. Perkembangan pesat perusahaan industri barang konsumsi berdampak pada semakin ketatnya persaingan antar perusahaan, sehingga menuntut perusahaan untuk memilih strategi yang tepat demi mempertahankan eksistensinya.

Penelitian-penelitian sebelumnya yang mengangkat tema ini sebenarnya sudah banyak, hal ini dikarenakan perlunya perusahaan menentukan jumlah kas yang harus dimiliki oleh perusahaan agar tidak terjadi kelebihan maupun kekurangan kas. Meskipun telah banyak penelitian yang sama sebelumnya, namun penulis memilih penelitian ini sebagai pembuktian apakah ada perbedaan keadaan antara masa penelitian sebelumnya dengan penelitian yang dilakukan ini yaitu dengan periode objek penelitian dan perusahaan yang berbeda.

\section{METODE}

Dalam hal ini pemilihan sampel berdasarkan pada karakteristik tertentu yang dianggap mempunyai sangkut paut dengan karakteristik populasi yang sudah diketahui sebelumnya (Umar, 2011). Karakteristik tersebut adalah sebagai berikut:

1. Perusahaan sektor industri barang konsumsi yang sudah dan masih terdaftar di Bursa Efek Indonesia pada tahun 2015-2018.

2. Perusahaan sektor industri barang konsumsi yang memiliki data lengkap selama periode pengamatan yaitu tahun 2015-2018.

3. Perusahaan sektor industri barang konsumsi yang membagikan dividen secara berturut-turut pada tahun 2015-2018.

Metode analisis data yang digunakan adalah analisis regresi berganda dengan menggunakan program SPSS sebagai alat untuk 
menguji data. Model analisis regresi berganda digunakan untuk menjelaskan hubungan dan seberapa besar pengaruh variabel-variabel bebas terhadap variabel dependen. Analisis regresi berganda dalam penelitian ini digunakan untuk mengetahui pengaruh growth opportunity, net working capital, cash conversion cycle, dan dividend payout terhadap cash holding perusahaan sektor industri barang konsumsi yang terdaftar di Bursa Efek Indonesia tahun 2015-2018. Metode analisis data yang digunakan dalam penelitian ini sebagai berikut:

\section{HASIL}

Hasil analisis statistik menunjukkan bahwa variabel growth opportunity mempunyai koefisien regresi sebesar 0,047 . Hasil statistik uji t untuk growth opportunity diperoleh nilai signifikansi sebesar 0,586, dimana hasil tersebut lebih besar dari $\alpha=0,05$. Hasil ini menunjukkan bahwa growth opportunity tidak berpengaruh terhadap cash holding, sehingga hipotesis pertama ditolak.

Tumbuh tidaknya aktiva tidak mempengaruhi cash holding. Hasil tersebut tidak sesuai dengan pecking order theory yang menyatakan bahwa perusahaan dengan growth opportunity yang tinggi akan menahan kas lebih sedikit cenderung menggunakan pendanaan eksternal (Gill dan Shah, 2012). Sebelumnya telah dijelaskan bahwa perusahaan dengan growth opportunity tinggi akan mendorong perusahaan untuk menahan kas dalam jumlah yang lebih banyak untuk membiayai kesempatan investasinya.

Hasil penelitian ini mendukung penelitian terdahulu yang dilakukan oleh Wulandari (2019). Hasil penelitian tersebut menyatakan bahwa growth opportunity tidak berpengaruh terhadap cash holding. Tetapi hasil penelitian ini berbeda dengan hasil penelitian yang dilakukan oleh Saputri (2019) yang menyatakan bahwa growth opportunity berpengaruh positif terhadap cash holding.

Hasil analisis statistik menunjukkan bahwa variabel net working capital mempunyai koefisien regresi sebesar 0,267 dengan probabilitas sebesar 0,000. Hasil ini menunjukkan bahwa net working capital berpengaruh terhadap cash holding, hasil ini sesuai dengan hipotesis kedua yang menyatakan bahwa net working capital berpengaruh terhadap cash holding, sehingga hipotesis kedua diterima.

Hasil penelitian ini sesuai dengan teori pecking order yang menyatakan bahwa perusahaan lebih mendahulukan pendanaan dari internal. Sehingga apabila net working capital bertambah maka cash holding juga akan bertambah. Selain itu, komponen dari net working capital atau modal kerja bersih adalah aset lancar dan hutang lancar, maka apabila aset lancar meningkat maka juga akan meningkatkan saldo cash holding.

Hasil penelitian ini mendukung penelitian terdahulu yang dilakukan oleh Wulandari (2019). Hasil penelitian tersebut menyatakan bahwa net working capital berpengaruh signifikan terhadap cash holding. Tetapi hasil 
penelitian ini berbeda dengan hasil penelitian yang dilakukan oleh Maarif (2017) yang menyatakan bahwa net working capital tidak berpengaruh terhadap cash holding.

Hasil analisis statistik menunjukkan bahwa variabel cash conversion cycle mempunyai koefisien regresi sebesar 0,000. Hasil statistik uji t untuk cash conversion cycle diperoleh nilai signifikansi sebesar 0,055 dengan menggunakan nilai signifikan $10 \%$ dimana hasil tersebut lebih kecil dari $\alpha$ $=0,10$ yang menunjukkan bahwa cash conversion cycle berpengaruh terhadap cash holding, sehingga hipotesis ketiga diterima.

Cash conversion cycle didefinisikan sebagai satuan hari yang diperlukan untuk mendapatkan kas dari hasil operasi perusahaan yang berasal dari penagihan piutang ditambah penjualan persediaan dikurangi dengan pembayaran utang (Syarief dan Wilujeng, 2009). Semakin pendek cash conversion cycle suatu perusahaan, semakin cepat perusahaan akan menerima kas. Selanjutnya kas tersebut dapat digunakan untuk diinvestasikan kembali ke perusahaan. Hasil penelitian ini sejalan dengan Pecking Order Theory bahwa semakin lama siklus konversi kas maka semakin besar juga kebutuhan pendanaan internal sehingga perusahaan cenderung menahan kas dalam jumlah besar. Sebaliknya, semakin cepat siklus konversi kas semakin baik bagi perusahaan, karena perusahaan akan menerima kas yang selanjutnya kas tersebut dapat digunakan untuk diinvestasikan kembali sehingga perusahaan akan menahan kas lebih sedikit.

Hasil penelitian ini mendukung penelitian terdahulu yang dilakukan oleh Hamendru (2018) yang menyatakan bahwa cash conversion cycle berpengaruh terhadap cash holding. Tetapi hasil penelitian ini berbeda dengan hasil penelitian yang dilakukan oleh Senjaya (2016) yang menyatakan bahwa cash conversion cycle tidak berpengaruh terhadap cash holding.

Hasil analisis statistik menunjukkan bahwa variabel dividend payout mempunyai koefisien regresi sebesar 0,030. Hasil statistik uji t untuk dividend payout diperoleh nilai signifikansi sebesar 0,418, dimana hasil tersebut lebih besar dari $\alpha=0,05$. Hasil ini menunjukkan bahwa dividend payout tidak berpengaruh terhadap cash holding, sehingga hipotesis keempat ditolak.

Pembayaran dividen tidak mempengaruhi cash holding. Hal ini diduga karena perusahaan pembayar dividen yang kekurangan dana bisa menghasilkan dana likuid yang low cost dengan mengurangi pembayaran dividen (Hapsari, 2015). Hasil penelitian tersebut tidak sesuai dengan trade off theory yang menyatakan bahwa dividend payout berpengaruh negatif terhadap cash holding. Perusahaan dapat menukar biaya marginal cash holding dengan mengurangi pembayaran dividen. Bates et al., (2009) mendukung temuan Han dan Qiu (2007) yang menyatakan cash holdings meningkat pada perusahaan yang tidak membayar dividen karena perusahaan yang tidak membayar dividen memiliki kendala finansial dan memiliki kendala untuk memasuki pasar kredit. Agar tetap 
bertahan, perusahaan yang tidak membayar dividen akan memegang kas lebih besar.

Hasil penelitian ini mendukung penelitian terdahulu yang dilakukan oleh Wulandari (2019) yang menyatakan bahwa dividend payout tidak berpengaruh terhadap cash holding. Tetapi hasil penelitian ini berbeda dengan hasil penelitian yang dilakukan oleh Wenny (2017) yang menyatakan bahwa dividend payout berpengaruh positif terhadap cash holding.

\section{KESIMPULAN}

Penelitian ini bertujuan untuk mengetahui pengaruh growth opportunity, net working capital, cash conversion cycle, dan dividend payout terhadap cash holding perusahaan sektor industri barang konsumsi yang terdaftar di Bursa Efek Indonesia periode 2015-2018. Hasil pengujian hipotesis dengan menggunakan analisis regresi linier berganda menunjukkan bahwa:

1. Growth opportunity tidak berpengaruh terhadap cash holding. Hal ini dibuktikan dengan nilai koefisien regresi growth opportunity yang bernilai 0,047 dan nilai signifikansi 0,586 , lebih besar dari nilai toleransi kesalahan $(0,586>0,05)$, sehingga $\mathrm{H}_{1}$ yang menyatakan bahwa growth opportunity berpengaruh terhadap cash holding ditolak.

2. Net working capital berpengaruh terhadap cash holding. Hal ini dibuktikan dengan nilai koefisien regresi net working capital bernilai positif sebesar 0,267 dengan probabilitas sebesar 0,000. Nilai signifikansi lebih kecil dari toleransi kesalahan $(0,000<0,05)$, hasil ini mendukung prediksi yang menyatakan bahwa net working capital berpengaruh terhadap cash holding. Oleh karena itu $\mathrm{H}_{2}$ yang menyatakan bahwa net working capital berpengaruh terhadap cash holding diterima.

3. Cash conversion cycle berpengaruh terhadap cash holding. Hal ini dibuktikan dengan nilai koefisien regresi cash conversion cycle sebesar 0,000 dan nilai signifikansi sebesar 0,055. Nilai signifikansi lebih kecil dari toleransi kesalahan $(0,055<0,10)$. Hal ini menujukkan bahwa $\mathrm{H}_{3}$ diterima, sehingga dapat disimpulkan bahwa cash conversion cycle berpengaruh terhadap cash holding perusahaan sektor industri barang konsumsi yang terdaftar di Bursa Efek Indonesia periode 2015-2018.

4. Dividend payout tidak berpengaruh terhadap cash holding. Hal ini dibuktikan dengan nilai koefisien regresi dividend payout bernilai negatif sebesar 0,030 dan nilai signifikansi sebesar 0,418. Nilai signifikansi lebih besar dari toleransi kesalahan $(0,418>0,05)$. Hal ini menujukkan bahwa $\mathrm{H}_{4}$ ditolak, sehingga dapat disimpulkan bahwa dividend payout tidak berpengaruh terhadap cash holding perusahaan sektor industri barang konsumsi yang terdaftar di Bursa Efek Indonesia periode 2015-2018. 
Berdasarkan kesimpulan dan keterbatasan pada penelitian ini, maka dapat disampaikan beberapa saran sebagai berikut :

1. Bagi Perusahaan

Diharapkan hasil penelitian ini dapat memberikan informasi mengenai konsep cash holding. Net working capital dan cash conversion cycle perlu diperhatikan oleh perusahaan dalam menentukan tingkat cash holding, karena net working capital dan cash conversion cycle terbukti memengaruhi cash holding perusahaan sektor industri barang konsumsi yang terdaftar di Bursa Efek Indonesia tahun 2015-2018.

2. Bagi Penelitian Selanjutnya

a. Penelitian selanjutnya sebaiknya menambahkan variabel independen lain yang kemungkinan memengaruhi cash holding perusahaan misalnya ukuran perusahaan, cash flow, dan leverage.

b. Penelitian selanjutnya diharapkan menganalisis cash holding pada sub sektor lain yang ada di sektor manufaktur selain sektor industri barang konsumsi, seperti sektor industri dasar dan kimia atau sektor aneka industri, atau dapat pula menganalisis cash holding di sektor lain diluar sektor manufaktur. Hal ini dimaksudkan agar dapat diperoleh gambaran yang detail dan dapat dibandingkan mengenai praktek pengelolaan cash holding di berbagai sektor perusahaan yang terdaftar di Bursa Efek Indonesia.

\section{DAFTAR PUSTAKA}

Al-Najjar, B. Dan Belghitar, Y. (2011). Corporate Cash Holdings and Dividend Payments: Evidance From Simultaneous Analysis. Managerial and Decision Economic.

Al-Najjar, B. Dan Belghitar, Y. (2013). The Financial Determinants of Corporate Cash Holdings: Evidance from some Emerging Markets. International Business Review. Vol 22 (1).

Bates, T. et al. (2009). Why do U.S Firms Hold so much more Cash than they used to?. Journal of Finance. LXIV (5).

Bigelli, M., Vidal, J.S. (2009). Cash Holdings in Private Firms. Journal of Banking \& Finance Vol 36, 26-35.

Brigham, E. F dan Houston, J.F. (2011). Dasar-dasar Manajemen Keuangan. Diterjemahkan oleh: Ali Akbar Yulianto, Buku 2, Edisi 11, Salemba Empat, Jakarta.

Christina, Yessica, dan Ekawati, Erni. (2013). Excess Cash Holdings dan Kepemilikan Institusional pada Perusahaan Manufaktur yang Terdaftar di BEI. Jurnal Universitas Kristen Duta Wacana, Yogyakarta-Indonesia.

Ferreira, Miguel A. Dan Antonio S. Vilela. (2004). Why Do Firms Hold Cash? Evidance from EMU Countries. European Financial 
Management. Vol. 10 (2).

Ghozali, Imam. (2011). Aplikasi Analisis Multivariate dengan Program SPSS 19. Semarang : Universitas Diponegoro.

Gill, Amarjit, Chairul Shah. (2012). Determinants of Corporate Cash Holdings: Evidance from Canada. International Journal of Economic and Finance. Vol. 4 (1).

Gumanti, Ary Tatang. (2013). Kebijakan Dividen Teori, Empiris dan Implikasi. Edisi 1. UPP STIM YKPN. Yogyakarta.

Hapsari, Ajeng Andriani. (2015). Faktor-faktor yang Mempengaruhi Jumlah Pemegangan Kas di Perusahaan. Jurnal Manajemen Bisnis Indonesia. Vol. 3 (1).

Harwanto. Feri Osa. (2016). Faktor-Faktor Yang Mempengaruhi Cash Holding Pada Perusahaan Yang Terdaftar di ISSI Tahun 2012-2014. Skripsi. Fakultas Ekonomi dan Bisnis Islam. UIN Sunan Kalijaga Yogyakarta.

Humendru, Anugerah. (2018). Faktor-Faktor yang Mempengaruhi Kebijakan Cash Holding (Studi Kasus pada Perusahaan Manufaktur yang Terdaftar di Bursa Efek Indonesia Tahun 2012-2015), Vol. 4 No. 1, Maret 2018.

Husnan, Suad. (1998). Manajemen Keuangan Teori dan Penerapan (Keputusan Jangka Pendek). Buku 2 Edisi 4. Yogyakarta : BTFE.

Jamil, Sulaman. (2016). Determinants of Corporate Cash Holdings: Empirical Analysis of Pakistani Firms. IOSR Journal of Economics and Finance, Volume 7 (3). May.-Jun. 2016. Faculty of Management and Administration sciences (FMAS). University of Gujrat. Pakistan.

Jinkar, Rebecca Theresia. (2013). Analisa Faktor-faktor Penentu Kebijakan Cash Holding Perusahaan Manufaktur di Indonesia. Jurnal Departemen Akuntansi Fakultas Ekonomi. Universitas Indonesia.

Maarif, Sjamsul. (2019). Pengaruh Interest Income Growth , Net Working Capital, dan Capital Expenditure terhadap Cash Holding dengan Aktivitas Dewan Komisaris sebagai Variabel Moderas. Jurnal Madani, Vol. 2, No. 1, Maret 2019. Fakultas Ekonomi dan Bisnis. Universitas Pancasila.

Marfuah, dan Ardan Zulhilmi. (2014). Pengaruh Growth Opportunity, Net Working Capital, Cash Conversion Cyrcle, dan Leverage terhadap Cash Holding Perusahaan. Jurnal Universitas Islam Indonesia.

Najema. (2019). Analisis Pengaruh Current Asset, Capital Expenditure, Cash Conversion Cycle, Cash Flow, Leverage, Market To Book Value Dan Net Working Capital Terhadap Cash Holdings Pada Sektor Industri Barang Konsumsi di BEI. Jurnal Sains Manajemen dan Kewirausahaan, Vol. 3, No. 1, Maret 2019. Fakultas Ekonomi dan Bisnis. Universitas Lambung Mangkurat. Banjarmasin.

Opler, Tim, Lee Pinkowitz, Rene Stulz, Rohan Williamson. (1999). The Determinants and Implications of Corporate Cash Holdings. Journal of Financial Economic, Vol.52 No.1.

Prasentianto, Hanafi. (2014). Analisis Faktor-faktor yang Mempengaruhi 
Tingkat Cash Holding.

Putrato, Wahyu Edi. (2017). Analisis Determinan Tingkat Cash Holding Perusahaan Property dan Real Estate yang Terdaftar di Bursa Efek Indonesia. Skripsi. Fakultas Ekonomi. Universitas Negeri Yogyakarta.

Rahmawati, Zahrotul Auliya. (2013). Faktor-faktor yang Mempengaruhi Keputusan Cash Holding pada Perusahaan Food and Beverages yang Terdaftar di Bursa Efek Indonesia. Jurnal Manajemen Fakultas Ekonomi dan Bisnis. Universitas Brawijaya.

Riyanto, Bambang. (2001). Dasar-dasar Pembelajaran Perusahaan. Buku 7 Edisi 4. Yogyakarta: BPFE Yogyakarta.

Safitri, Puput. (2016). Pengaruh Net Working Capital, Board Size, Growth Opportunity, Net Working Capital dan Cash Conversion Cycle terhadap Cash Holdings Perusahaan Sektor Industri Barang dan Konsumsi yang terdaftar di BEI tahun 2012-2014.

Saputri, Erdian. (2019). Pengaruh Profitabilitas, Leverage, Firm Size, dan Growth Opportunity terhadap Cash Holding Perusahaan (Studi Kasus Perusahaan Manufaktur yang Terdaftar pada Bursa Efek Indonesia Periode Tahun 2013-2017). Journal of Entrepreneurship, Management, and Industry, Vol. 2, No. 2, (2019). Program Studi Manajemen FEIS. Universitas Bakrie. Jakarta.

Senjaya, Sheryl Yuliana. (2015). Analisis Pengaruh Investment Opportunity Set, Cash Conversion Cyrcle, dan Corporate Governance Terhadap Cash Holding. Tesis. Universitas Udayana.

Simanjuntak, Saul Fernando. (2017). Faktor-Faktor yang Mempengaruhi Cash Holding Perusahaan. Jurnal Bisnis dan Akuntansi, Vol. 19, No. 1a. November 2017. STIE Trisakti.

Subramanyam et al, (2011). Firm Structure and Corporate Cash Holdings. Journal of corporate finance. Vol 17.

Sugiyono. (2009). Metode Penelitian Bisnis (Pendekatan Kualitatif, Kuantitatif, dan R\&D). Bandung: Alfabeta.

Sutrisno, Bambang. (2018). Likuiditas Saham dan Cash Holding di Indonesia. Jurnal IImu Akuntansi. Vol. 11 (1).

Syafrizaliadhi, Adhitya Dasha. (2014). Faktor-Faktor yang Memengaruhi Perilaku Cash Holding pada Perusahaan Besar dan Perusahaan Kecil. Skripsi. Universitas Diponegoro.

Syarief, Moch. Ednan, dan Wilujeng, Ita Prihatining. (2009). Cash Conversion Cycle dan Hubungannya dengan Ukuran Perusahaan, Profitabilitas, dan Manajemen Modal Kerja. Jurnal Ekonomi dan Bisnis, Tahun 14 Nomor 1 Maret 2009.

Umar, Husein. (2011). Metode Penelitian untuk Skripsi dan Tesis Bisnis. Jakarta: PT. Rajagrafindo Persada.

Wenny, Shara Mustika. (2017). Analisis Faktor-Faktor yang Mempengaruhi Cash Holdings pada Perusahaan Manufaktur yang Terdaftar di Bursa Efek Indonesia Tahun 2013-2015 (Pengujian Teori Trade-Off). Skripsi. Fakultas Ekonomi dan Bisnis. Universitas 
Lampung.

Wijaya, Anggita Langgeng, Bandi, dan Sri Hartoko. (2010). Pengaruh Kualitas Akrual dan Leverage Terhadap Cash Holding Perusahaan. Jurnal Akuntansi dan Keuangan. Vol 7- No 2, Desember 2010.

William, dan Syarief Fauzi. (2013). Analisis Pengaruh Growth Opportunity, Net Working Capital, dan Cash Conversion Cyrcle terhadap Cash Holdings Perusahaan Sektor Pertambangan. Jurnal Ekonomi dan Keuangan, Vol. 1, No. 2.

Wulandari, Endah Ayu. (2019). Pengaruh Growth Opportunity, Net Working Capital, Cash Conversion Cycle dan Dividend Payout terhadap Cash Holding (Studi Empiris pada Perusahaan Property dan Real Estate yang Terdaftar di Bursa Efek Indonesia Tahun 20142017). Jurnal Eksplorasi Akuntansi, Vol. 1, No. 3, Agustus 2019. Jurusan Akuntansi Fakultas Ekonomi. Universitas Negeri Padang. 